\title{
Development of Fusion Fuel Cycles: Large Deviations from US Defense Program Systems
}

\author{
James Edward Klein ${ }^{\mathrm{a}}$, Anita Sue Poore ${ }^{\mathrm{a}}$, David W. Babineau ${ }^{\mathrm{a}}$ \\ ${ }^{a}$ Savannah River National Laboratory, Aiken, SC USA
}

\begin{abstract}
Fusion energy research is dominated by plasma physics and materials technology development needs with smaller levels of effort and funding dedicated to tritium fuel cycle development. The fuel cycle is necessary to supply and recycle tritium at the required throughput rate; additionally, tritium confinement throughout the facility is needed to meet regulatory and environmental release limits. Small fuel cycle development efforts are sometimes rationalized by stating that tritium processing technology has already been developed by nuclear weapons programs and these existing processes only need rescaling or engineering design to meet the needs of fusion fuel cycles. This paper compares and contrasts features of tritium fusion fuel cycles to United States Cold War-era defense program tritium systems. It is concluded that further tritium fuel cycle development activities are needed to provide technology development beneficial to both fusion and defense programs tritium systems.
\end{abstract}

Keywords: Tritium processes, tritium confinement, tritium purification, tritium storage, DT fusion

\section{Introduction}

Deuterium and tritium are heavy isotopes of protium (hydrogen) and were discovered in 1931 and 1934, respectively. Radioactive tritium has a half-life of about 12.3 years and emits a very weak beta particle, decaying to helium-3 $\left({ }^{3} \mathrm{He}\right)$. The fusion reaction between a deuterium and tritium atom produces helium-4, a neutron, and $17.59 \mathrm{MeV}$ of energy. Research into United States military applications of D-T fusion energy began in the 1940s during the Manhattan Project, with the first large-scale weapons test occurring in 1952. The D-T fusion reaction is also attractive as controlled thermonuclear fusion for civilian power generation purposes, with research starting in the 1950s.

Process supplied tritium that is not lost, consumed, or decayed to helium, is recovered, purified, separated, and then reused in what can be described as a fuel cycle. Figure 1 shows a simplified block diagram of a tritium fuel cycle which possesses the basic processes for any use of tritium.

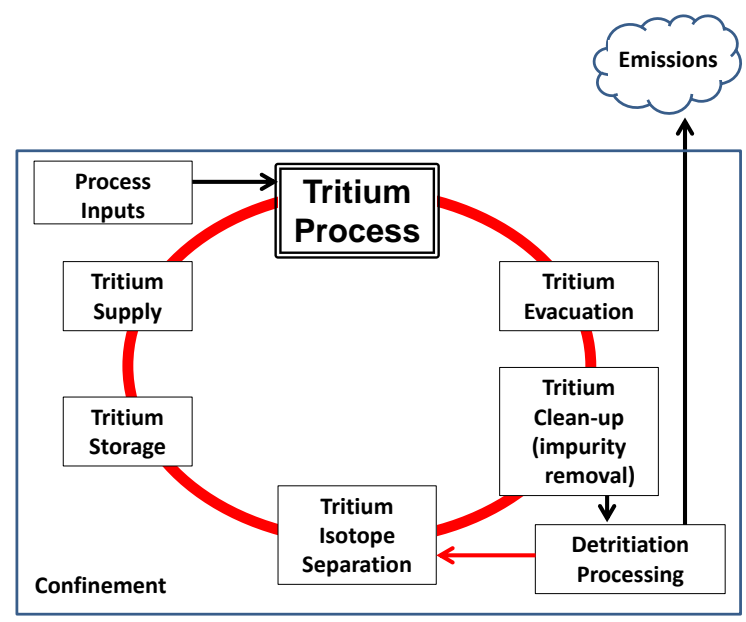

Fig. 1. Typical Tritium Fuel Cycle
The starting point for any tritium fuel cycle is the "Tritium Process". The Tritium Process can vary from loading tritium into defense application components, glass tubes for EXIT signs, or into fusion research machines such as ITER or the National Ignition Facility (NIF). In addition to development of the Tritium Process which uses tritium, technology development is necessary for the remaining processes/steps of the tritium fuel cycle. These processing steps are common to all uses of tritium though the specific technologies utilized will vary depending on the specific requirements of the processing steps (e.g. flow, concentration, etc.). Although the number of process blocks shown in Fig.1 is relatively small, the technology selection for these processing blocks can vary greatly based on the requirements of the Tritium Process.

Large scale production of tritium, by neutron irradiation of materials containing Li-6, started in the 1950 's to support its use in US defense program as part of a nuclear weapons deterrent. Commercial chemical companies such as DuPont were asked by the US government to design, build, and operate facilities to support the needs of the nations' defense programs. As defense program stockpile needs increased, larger throughput facilities were designed and constructed. Although lagging in development activities and funding, fusion research programs were also being conducted concurrently.

Fusion research can be broadly broken into three main topical areas: fusion plasma physics, materials, and the tritium fuel cycle. As research programs developed, funding was mostly devoted to D-T physics and materials development with relatively little funding directed for fuel cycle development. It was commonly perceived that defense program tritium technologies could be easily adapted and deployed for use in fusion fuel cycles, and thus little development effort was needed: it is just a matter of engineering/scaling the fuel 
cycle processes to meet the needs of the selected use of tritium.

This purpose of this paper is to compare and contrast the various feature of tritium fuel cycles for Cold War era, US defense program-based tritium processes to current fuel cycles proposed for fusion energy research. Comparisons will be made in numerous areas including tritium processing demands, facility siting, emissions, and waste disposal.

\section{US Defense vs Fusion Fuel Cycles}

\subsection{Tritium Supply}

The tritium supply for US defense program applications is part of an integrated program to ensure adequate supplies of tritium (and other nuclear materials) for current and future stockpile needs. Facilities such as the Savannah River Site (SRS) were constructed to produce tritium for defense programs. Tritium production required design, construction, and operations of target and fuel fabrication facilities, heavy water reactors, spent fuel storage and processing facilities, and waste burial grounds in addition to the tritium extraction and processing facilities. The need for a site with all these facilities created a large over-head cost for tritium production, but was considered necessary to support a nuclear deterrent weapons programs. In the US, tritium is currently produced in a commercial light water reactor and extracted at SRS.

Although tritium breeding is part of many fusion energy research programs, initial tritium supplies will be purchased. The US Department of Energy (DOE) discontinued the commercial sale of tritium in the 1990's. Tritium produced from operating CANDU reactors can be removed from heavy water at the Darlington Tritium Removal Facility (DTRF) in Ontario, Canada; tritium is a waste by-product of its commercial power production. Some recovered tritium is transported to the AECL Chalk River Laboratory for dispensing and shipment to customers as part of a commercial sales program. Various studies (e.g. Ref. 1) estimate the consumption rate of the tritium available at the DTRF, but it is not known if any procurement contracts have actually been placed for purchase of the tritium in fusion applications.

\subsection{Tritium Facility Siting and Emissions}

Various sites ${ }^{2}$ were selected for development of the US Nuclear Weapons Complex during and after the World War II Manhattan Project. The sites for handling large quantities of nuclear materials were typically located away from large population areas, on large parcels of land, and near rivers. Remote locations aided security measures, but in some instances, small population centers were relocated for construction of these sites.

The distance from tritium (and other nuclear material) facilities to the site boundary are/were on the order of miles, reducing radioactive consequences to the public in the event of material releases. The large land areas were also used for disposal of some industrial and radioactive wastes since they were located away from the public. Disposal practices during early operations of these sites have evolved to current practices which require permitted facilities.

In early operations of these sites, limiting environmental releases of tritium was given a lower priority than the urgency of meeting Cold War production demands. Accidental material releases were given less scrutiny than current regulations and practices. Large land areas within site boundaries allowed for relatively inexpensive disposal of waste materials. Onsite storage and disposal facilities also reduce the risk of radioactive material releases from transportation accidents.

In contrast, many fusion energy research programs are conducted at Universities or research institutes which may be located in or near urban settings. ${ }^{3}$ The colocation of these tritium handling facilities with population areas provide greater radiological consequences, and thus lower tritium release limits are necessary compared to defense program sites with larger site boundaries. Discharges of even low levels of tritium are given a high degree of scrutiny compared to former defense program practices. On-site waste disposal is usually prohibited and waste is packaged and transported to off-site disposal facilities - sometimes DOE sites.

\subsection{Tritium Process Inventory}

During the Cold War era, there were a tremendous amount of nuclear materials produced - including tritium. The production supply was established, and excess material was stored until needed. Excess material was seen as an asset - having material available for use, instead of considered a liability in the event of an accident. The cost of material production was part of an overall defense program plan and budget with little emphasis given on minimizing the process inventory since the primary goal was meeting defense needs and production demands.

In fusion energy systems, tritium inventories are designed to be as small as possible to meet the goals of the program for several reasons. One reason is the larger the tritium inventory, the larger the budget needed for purchase, shipping, and storage of tritium. With the tritium inventory decaying approximately $5.6 \%$ per year, larger material purchases are required to replace material which has decayed to He-3.

Another reason for small fusion system tritium inventories are potential dose consequences to the public under hypothetical accident scenarios. Larger, releasable tritium inventories represent larger dose consequences to the public, so smaller inventories represent smaller public dose risks. Larger inventories will also likely require additional mitigation strategies (e.g. process systems or equipment) to minimize releases to the public. In the case of ITER, process vessels are allowed a maximum of $70 \mathrm{~g}$ tritium per vessel for safety reasons. Processes which require large quantities of tritium 
require more capital and operating costs (more vessels and instruments) for operating the desired process.

\subsection{Tritium Processing}

One great difference between US defense program and some fusion research tritium systems is the batch operations needed for defense or industrial applications, while continuous tritium process operations are needed for fusion. Whether filling defense program components or EXIT sign tubes with tritium mixtures, these operations are inherently batch processes. Discrete units are prepared, filled, and removed from the Tritium Process step of Fig. 1 before the next set of items are introduced into the process step. The same can be said of the tritium recovery step where the same items can be opened for tritium recovery and recycle.

In the case of ITER, batch operations would dramatically increase the process inventory if all the tritium needed for an experiment had to be available in the storage and delivery system (SDS). More storage vessels would be needed for batch operations not only for the tritium supply, but also for collection and storage of the D-T mixtures exhausted from the tokamak. ITER operating in a continuous flow mode significantly reduces the required tritium inventory for operations.

\subsection{Tritium Process Flow}

The processing rates in US defense program facilities are protected information and are declared, "DPBaseline" rates for comparison. In the case of ITER and DEMO fuel cycles, these process flow rates are significantly larger than the DP Baseline rates. The pros and cons of these faster flow rates are discussed later.

\section{Discussion}

Differences between US Cold War-era defense programs Tritium Processes and the ITER Fuel Cycle are assessed for each step of the typical tritium fuel cycle. The defense programs Tritium Process is the filling of tritium gas mixtures into discrete defense program components whereas for ITER, the Tritium Process is the tokamak fusion process. In both cases, tritium is introduced into the process and mixed with other gases to start the fuel cycle.

\subsection{Tritium Evacuation}

The second block of Fig. 1 illustrates tritium removal or evacuation from the process. For defense programs, there are two different, discrete out-flows of tritium: residual tritium from the filling operation and tritium recovered from returned components. For these evacuations, traditional vacuum pumps can be used for tritium removal with the residual process tritium content determined by system design and time allocated to gas evacuation. For ITER, the tritium feed and exhaust can be considered mostly a steady-state process for the duration of a plasma test. In this case, the evacuation pumps must able to evacuate the tokamak to low pressures continuously during the course of an experiment with flow rates up to $200 \mathrm{Pam}^{3} \mathrm{~s}^{-1}$ (118 standard liters per minute at standard temperature and pressure of $1 \mathrm{~atm}$ and $\left.0^{\circ} \mathrm{C}\right) .^{4}$

\subsection{Tritium Clean-Up}

The Tritium Clean-up block in Fig. 1 is similar for both defense program systems and ITER where diffusers/permeators perform the major separation of tritium (hydrogen isotopes) from other impurities. The separated tritium is later isotopically separated and then stored for reuse. The processes using tritium very greatly and each process will have different requirements for impurity removal. The amount of impurities and the relatively large flow rates for fusion applications, along with the intentional introduction of non-hydrogen isotopes into some fusion processes (e.g. inertial confinement fusion) will drive the need for different clean-up technologies and processes.

\subsection{Detritiation Processing}

The processes used for (tritium) contaminated gas processing can vary greatly between different tritium facilities performing similar processes. In almost all large scale tritium processes there is eventually a tritium removal step which relies upon tritium oxidation to form water and capture of this water using molecular sieve materials. The detritiation processes selected are many times driven by permitted or allowable tritium emissions from the facility as gaseous or solid waste. For example, "cracking" of tritium oxide by hot metals to release tritium gas and to form metal oxides for waste disposal has been used in defense program facilities and is expensive, but economical at the required processing rates. However, the processing demands of the ITER detritiation systems make the use of metal oxides for water cracking impractical. The ITER detritiation systems rely on continuous regenerable technologies to meet the regulatory requirements for environmental emissions and waste generation.

\subsection{Tritium Isotope Separation}

Little will be said about the tritium isotope separation systems (ISS) used in defense programs or fusion systems. The ISS processes are usually multistage/multi-column processes for processing and separating the H-D-T isotopes. The ISS process, along with tritium storage, almost invariably contains the largest fraction of the facilities tritium inventory.

\subsection{Tritium Storage}

Tritium storage technology relies mostly on metal hydride beds. For US defense program applications, a large tritium inventory can be considered an asset allowing flexibility and reliability in meeting process operational demands. In contrast, fusion fuel cycles strive to maintain the smallest practical tritium inventory necessary to operate the process. The goal to minimize process tritium inventories for fusion fuel cycle systems requires faster thermal cycle times than Defense Program hydride beds: faster cycle times for fusion fuel cycles minimizes the number of tritium storage beds and vessels necessary to support process operations. 


\subsection{Tritium Supply}

Methods to supply tritium to the Tritium Process vary greatly based on the demands of the process. For defense program components, traditional pumps and compressors or metal hydride beds can be used for gas movement. For ITER fueling rates, a combination of pumps along with specialized cryogenic pellet formers and injectors are necessary to operate the process.

\subsection{Process Inputs}

Most Tritium Processes have gases added to support process operations (e.g. deuterium). Other Process Inputs are impurities that enter the process flow which require removal. For example, interactions of tritium with process materials or in-leakage gases can produce protium, methane, water, or ammonia which are processed for tritium recovery to reduce facility emissions.

\subsection{Rate-Inventory Matrix}

Fig. 2 shows a matrix of relative tritium processing rates and inventories of the defense program systems and the ITER process. With decreased US defense program stockpile needs, it seems a review of current tritium process systems should be conducted and changes to the tritium processes should follow along path "A" shown in the figure: a path to lower inventory, faster processes.

In practice, high gas processing rates may not be needed for all defense program processes, but almost any tritium system can benefit by developing processes which have less process tritium hold-up. Initial efforts to improve defense program systems should look primarily for technologies that follow along path "1" shown in the Fig. 2. If higher processing rates produce reduced tritium inventories, the technologies can be optimized by then following the step " 2 " shown in the figure.

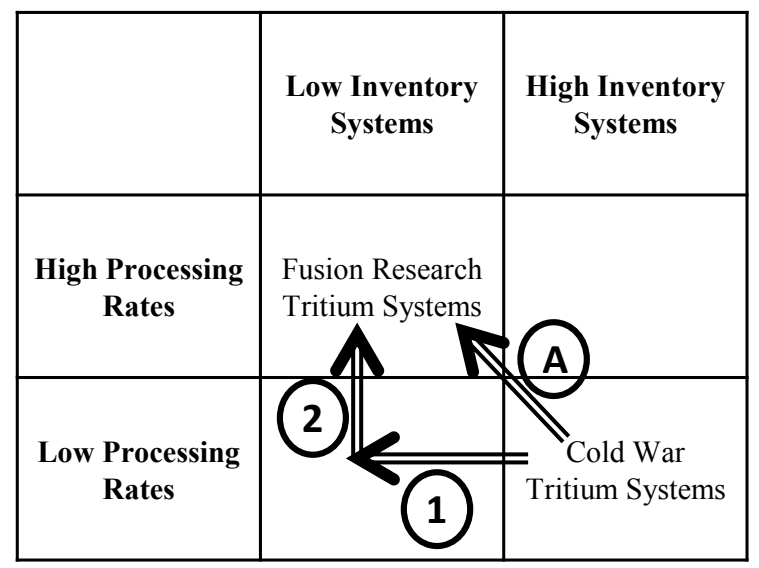

Fig. 2. Processing Rate - Inventory Matrix.

As with any system design, there will be trade-offs on proposed system design which needs to weigh lifecycle costs as part of technology selection and maturation. Even though the goal of US defense program systems may be to reduce process inventory and utilize higher processing rate systems, this does not imply the same technologies used for ITER-like system are applicable or even desirable for the defense tritium systems. As defense programs tritium process development activities created initial tritium technologies which could be analyzed for application to fusion fuel cycle systems back in the 1950s, new technologies developed for fusion systems can also be analyzed for utilization for defense program need. Tritium technology development benefits both fusion programs and defense programs, and results in minimizing the amount of tritium exposure to the public.

\section{Conclusions}

US Defense program tritium technologies were the baseline technologies for the development of US fusion fuel cycle systems. The demand for low tritium inventory systems for fusion fuel cycles requires higher tritium processing rates than Cold War-era tritium systems and thus the development of new or improved tritium processes. The common goal of minimizing tritium exposure to the public creates synergy between fusion and defense programs technology development activities. By sharing the results of new or innovative tritium processing technologies, defense programs AND fusion tritium facilities can be "right-sized" for their intended function.

\section{Acknowledgments}

This manuscript has been authorized by Savannah River Nuclear Solutions, LLC under contract No. DEAC09-08SR22470 with the US Department of Energy. The United States Government retains and the publisher, by accepting this article for publication, acknowledges that the United States Government retains a non-exclusive, paid-up, irrevocable, worldwide license to publish or reproduce the published form of this work, or allow others to do so, for United States Government purposes.

\section{References}

[1] Muyi Ni, Yongliang Wang, Baoxin Yuan, Jieqiong Jiang, and Yican Wu, "Tritium Supply Assessment for ITER and DEMOnstration Power Plant," Fusion Eng. Design, 88, (2013) 2422-2426.

[2] "50 Years of Excellence in Science and Engineering at the Savannah River Site", Chapter "The Genesis of the Savannah River Site Key Decisions, 1950," by J. Walter Joseph and Cy. J. Banick. Savannah River Site Manuscript WSRC-MS-2000-00061, May 17, 2000.

[3] "Environmental Assessment and (FONSI): The Tokamak Fusion Test Reactor Decontamination and Decommissioning Project and the Tokamak Physics Experiment at the PPPL", EA-0813, Dec. 5, 1994.

[4] D. Babineau, M. Glugla, S. Maruyama, R. Pearce, Li Bo, B. Rogers, S. Willms, G. Piazza, T. Yamanishi, S. H. Yun, L. Worth, and W. Shu, "Review of the ITER Fuel Cycle Systems," $23^{\text {rd }}$ IAEA Fusion Energy Conference, Daejon, South Korea, October 11-16, 2010. 